\title{
La epigenética: ¿el regreso de Lamarck?
}

\author{
Epigenetics: the return of Lamarck?
}

Laura M. Benítez-Cojulún

Escuela de Ciencias Físicas y Matemáticas, Universidad de San Carlos de Guatemala

*Autor al que se dirige la correspondencia: laurambenitezc@ecfm.usac.edu.gt

Recibido: 16 de octubre 2017 / Revisión: 02 de marzo 2018 / Aceptado: 08 de mayo 2018

\section{Resumen}

$\mathrm{D}$ esde hace algunos años, numerosas publicaciones sugieren un regreso de Lamarck gracias a los hallazgos de la epigenética, puesto que este campo de investigación parece desempolvar la idea de la herencia de caracteres adquiridos. Un vistazo a la historia de las ciencias de la vida, a escritos del siglo XIX de Lamarck y al Origen de las Especies de Darwin revela que esta nueva popularidad de Lamarck se basa en varias creencias equivocadas: (1) que Lamarck fue el primero en proponer la idea de la herencia de caracteres adquiridos; (2) que esa idea era el punto más singular de su teorización sobre la evolución de los seres vivos; (3) que Darwin no compartía esa creencia. En realidad, parte de la confusión se ha generado por el calificativo de "neodarwiniana" que suele asignársele a la llamada síntesis moderna, la cual combina aportes de Darwin, de Mendel y de Weismann, siendo este último un gran opositor a la idea de la herencia de caracteres adquiridos. Respecto a los hallazgos de la epigenética, dentro de la cual hay espacio tanto para la transmisión de caracteres adquiridos como para el concepto de selección natural, tal vez sería más certero hablar del regreso de los neolamarckianos franceses, o incluso de cierto naturalista muy conocido, cuya creencia en la herencia de caracteres adquiridos es mucho menos conocida: el mismo Darwin.

\footnotetext{
Abstract

Tor some years, many publications are suggesting a return of Lamarck due to the findings of epigenetics, because This research field seems to dust off the idea of the inheritance of acquired characters. A closer look to the history of life sciences, to some nineteenth-century Lamarck's writings and to The Origin of Species by Darwin reveals that this new popularity of Lamarck is based on several misconceptions: (1) that Lamarck was the first to propose the idea of the inheritance of acquired characters; (2) that this idea was the most singular point in his theorizing about the evolution of living beings; (3) that Darwin did not share this belief. Actually, part of the confusion is due to the label "neo-Darwinian" often applied to the so-called modern synthesis, given that this one combines ideas coming from Darwin, Mendel and Weismann, and the latter was a strong opponent of the idea of the inheritance of acquired characteristics. As far as epigenetic findings are concerned, within which there is room both for the inheritance of acquired characters and for the concept of natural selection, it would possibly be more accurate to talk about the return of French neo-Lamarckians, or of a certain famous naturalist whose belief in the inheritance of acquired characters is far less famous: Darwin himself.
} 


\section{Introducción}

Desde hace algunos años, se evoca frecuentemente el nombre de Lamarck en relación con el campo de la epigenética (Balter, 2000; Burkhardt, 2013), un nombre que, de por sí, está cada vez más presente en la literatura científica (Bucher, 2013; Burggren, 2014). Algunos títulos incluyen el nombre del investigador francés de una manera sugerente y hasta provocativa, por ejemplo "Why Lamarck won’t go away" (Ho, 1996), "Inheritance of acquired traits in plants: Reinstatement of Lamarck” (Sano, 2010), "Science of epigenetics: Lamarck was right after all" (Sawan \& Parvizi, 2013) o incluso "Epigenetics as a source of variation in comparative animal physiology -or- Lamarck is lookin' pretty good these days" (Burggren, 2014). Sano (2010) llega a proponer que se reevalúen las teorías de Lamarck para rescatar su reputación. Otros autores, más prudentemente, se han decidido por un título en forma interrogativa: "Was Lamarck just a little bit right?" (Balter, 2000), “¿Vuelve Lamarck?” (Francès, 2012), “The return of Lamarck?” (Bucher, 2013) o "Epigenética: ¿vuelve el Lamarckismo?” (Ruiz Rejón, 2015), por mencionar algunos.

Tomando en cuenta que Lamarck desarrolló su sistema teórico evolutivo hacia principios del siglo XIX, cabe preguntarse a qué se debe la reciente aparición de este discurso que sugiere el restablecimiento de su sistema teórico. Ello es especialmente interesante dado que dicho discurso asocia ese resurgimiento con descubrimientos en el campo de la epigenética, el cual empezó a desarrollarse como tal sobre todo a finales del siglo XX.

Una primera respuesta se impone rápidamente. Se trataría del regreso de la idea de la herencia de caracteres adquiridos, la cual había ido perdiendo terreno desde finales del siglo XIX, hasta quedar completamente derrotada a mediados del siglo XX, al menos en el mundo de los genetistas occidentales (Landman, 1993). Para responder menos precipitadamente a la interrogante que se plantea, a continuación se examinan con mayor detenimiento algunas ideas evolutivas de Lamarck, enseguida se explora el lugar que la herencia de caracteres adquiridos ocupa en el campo de la epigenética, para finalmente decidir si el discurso en cuestión parece justificado.

\section{La evolución según Lamarck}

Antes de presentar algunos de los puntos importantes de las ideas evolucionistas de Lamarck, es necesario esbozar ciertas circunstancias contextuales en medio de las cuales las propuso y desarrolló. En 1793, París empieza a contar con un Museo (Nacional) de Historia Natural, la institución prácticamente nueva en que se convirtió el antiguo Jardín del Rey (David, Cohen, \& Dessaint, 2009). Pues bien, es ahí y en ese entonces cuando Lamarck obtiene la cátedra de los insectos, los gusanos y los animales microscópicos (Burkhardt, 2013).

De hecho, algunas de sus ideas relacionadas con la evolución de los seres vivos pueden encontrarse en su obra Sistema de los animales sin vértebras, publicada a principios del siglo XIX y que correspondería a su curso impartido en 1800 dentro del marco ya mencionado (Burkhardt, 2013). Lamarck (1801) la dirigió explícitamente a sus alumnos y a otros estudiantes del país (Francia); en otras palabras, se trataba prácticamente de un libro de texto.

Ya en la parte introductoria de ese libro (el discurso de apertura pronunciado al inicio de su curso del año), Lamarck manifiesta que los invertebrados muestran, más claramente que los vertebrados, una "degradación" (un gradiente, en sentido decreciente, podríamos decir) en la organización y en las "facultades" de los animales, desde los más complejos hasta los más simples. Enseguida, plantea la sospecha de que son estos últimos, los más simples, los primeros que surgieron y que, posteriormente, "la naturaleza [...] con ayuda de mucho tiempo y de circunstancias favorables, formó a todos los demás" (Lamarck, 1801, pp. 11-12).

Respecto a los amplios períodos de tiempo requeridos, el historiador Burkhardt (2013) señala que, a juzgar por algún escrito ulterior, Lamarck tenía en mente miles o millones de siglos (algo que no deja de ser asombroso, pues era poco común para la época).

En cuanto a lo que Lamarck entendía por circunstancias favorables, estaban estrechamente ligadas a lo que hoy consideraríamos factores ambientales. En sus propias palabras, ellas nacían "de la influencia de los climas, de las variaciones de la temperatura de la atmósfera [...], de la diversidad de los lugares", etc. Lo interesante es que en esta lista, incluye la influencia "de los hábitos, de los movimientos, de las acciones [...]". Más adelante, Lamarck expone dos ideas acerca de las llamadas facultades de los animales: (1) que a consecuencia de las influencias aludidas, esas faculta- 
des aumentaban y se fortalecían conforme los animales hacían uso de ellas; (2) que esas mismas facultades se diversificaban gracias a los nuevos hábitos que hubieran sido conservados durante mucho tiempo. Esta diversificación implicaba entonces el surgimiento de modificaciones en órganos y partes del cuerpo en general. Esos cambios, según la visión de Lamarck, se conservaban y se propagaban por medio de la "generación" (Lamarck, 1801). Aquí debe tomarse en cuenta que, en el contexto académico correspondiente, el concepto de generación estaba muy asociado con el actual concepto de reproducción (excepto en el caso de la "generación espontánea", que ocurría sin progenitores).

También en algunas publicaciones posteriores, Lamarck desarrolló posturas acerca del origen y la evolución de los seres vivos. Por ejemplo, compartía la idea de la generación espontánea, que para él consistía en la transformación de materia no viva en "tejido celular" (Lamarck, 1809) bajo ciertas condiciones favorables (como el calor) y gracias a un "fluido sutil" y penetrante. Así podían surgir los seres vivos más simples que, en generaciones sucesivas, iban dando paso a organismos más complejos, con órganos cada vez más numerosos y especializados. La manera en que dicha complejidad se iba acrecentando era por la influencia de fluidos internos que (mediante su naturaleza, sus cambios, movimientos, pérdidas y ganancias) iban causando modificaciones en las partes y órganos de cada organismo. A esto contribuían también las influencias de las "circunstancias" que ya se mencionaron, por ejemplo factores ambientales y hábitos. Posteriormente, era posible que ciertas modificaciones (que ahora se calificarían de adquiridas), mantenidas por largo tiempo, se transmitieran a la descendencia. Así, según Lamarck, la gran diversidad de "circunstancias" existentes había contribuido a la formación de las múltiples formas de vida presentes, en el transcurso de muchísimo tiempo (Lamarck, 1802).

Ya se vio que en el caso de los animales, tales "circustancias" incluían a los hábitos. En tal sentido, en varias de sus publicaciones Lamarck insistió en ilustrar mediante ejemplos que algunas características de los animales, como las patas curvadas de las aves perchadoras, las extremidades membranosas de los murciélagos... o el famoso cuello de las jirafas, eran consecuencia de sus hábitos, y no a la inversa (Burkhardt, 2013; Lamarck, 1802).

Así, en su Filosofía zoológica, Lamarck (1809) enunció dos principios como leyes. Según la primera de esas leyes, el uso de los órganos conllevaba, a la larga, su fortalecimiento y crecimiento, mientras que su falta de uso, si era prolongada, causaba su debilitamiento, deterioro o incluso desaparición. La segunda ley se refería a la transmisión de esas modificaciones adquiridas a los descendientes, indicando que se producía si y solo si tales modificaciones eran comunes a los progenitores.

Se puede identificar, entonces, inmersa en la teorización lamarckiana, la famosa idea de la herencia de caracteres adquiridos. Pero esa idea por sí sola no era en absoluto una originalidad de Lamarck: en su contexto, era una idea común (Burkhardt, 2013; Choi \& Mango, 2014; Landman, 1993). Tampoco era el punto medular de su teorización (Burkhardt, 2013). De hecho, en su discurso de apertura del curso impartido a sus alumnos en 1802, la observación que Lamarck enfatiza como novedosa, de la cual pareciera estar orgulloso, es la del gradiente anteriormente mencionado, desde los animales más simples en organización, hasta los más complejos, con un correspondiente aumento progresivo de sus "facultades". Según Lamarck, se trababa de un hecho "que a pesar de su evidencia, no parece para nada haber llamado la atención de los naturalistas" (Lamarck, 1802, p. 12). Por el contrario, al referirse a la herencia de caracteres adquiridos, alguna vez escribió:

[...] esta ley de la naturaleza que hace transmitir a los nuevos individuos, todo lo que fue adquirido en la organización, durante la vida de los que los produjeron [los padres], es tan cierta, [...] tan probada por los hechos, que no hay ningún observador que no haya podido convencerse de su realidad (Lamarck, 1815-1822, p. 200).

Parece muy probable que Lamarck no habría podido sospechar que en el futuro se le atribuiría la paternidad de la idea de la herencia de caracteres adquiridos, pero ello seguramente quedará más claro en la tercera parte de este ensayo. A continuación se examina la relación entre esa vieja idea y el campo de la epigenética.

\section{La epigenética y la herencia de caracteres adquiridos}

El término epigenetics habría sido originalmente propuesto por Conrad Hal Waddington en 1942 (como se citó en Burggren, 2014; Locker, s.f.) pero, desde entonces, múltiples definiciones de ese término han estado en circulación (Burggren, 2014; Choi \& Mango, 2014; Heard \& Martienssen, 2014). Dado que el presente aná- 
lisis se centra en la asociación entre la epigenética y el nombre de Lamarck, las definiciones que interesan aquí son las que relacionan ese campo de investigación con la posibilidad de transmitir a la descendencia fenotipos adquiridos, particularmente en respuesta a cambios ambientales.

En ese sentido, la definición de epigenética considerada más amplia o tradicional es la que le atribuye a ese campo la tarea de estudiar la herencia transgeneracional (i.e. que se mantiene por generaciones, aunque este término también es un tanto polémico) de fenotipos nuevos que no se explican por cambios en la secuencia de los nucleótidos del genoma, es decir, que no se deben a mutaciones clásicas (Burggren, 2014; Choi \& Mango, 2014; Heard \& Martienssen, 2014). Este tipo de definiciones provendrían de la que el biólogo Nanney (1958) propuso originalmente, como lo señala repetidas veces Haig (2004; 2007; 2012). Lo que Nanney había hecho era considerar genéticos a los mecanismos de mantenimiento y replicación de una "biblioteca" de especificaciones, tanto expresadas como no expresadas, y epigenéticos a los "mecanismos auxiliares [...] involucrados en determinar cuáles especificaciones deben ser expresadas en cualquier célula particular" (Nanney 1958, 712).

También existen definiciones más recientes que se refieren explícitamente a la influencia del ambiente sobre la expresión de los genes y la cromatina (Heard $\&$ Martienssen, 2014). No está de más recordar que la cromatina es el conjunto formado por el ADN y las proteínas a él asociadas (entre ellas, las histonas).

En las últimas décadas (sobre todo desde los años noventa, según puede inferirse indirectamente a partir de observaciones de Nicolosi y Ruivenkamp (2012) y de Morange (2013), por ejemplo), la epigenética ha avanzado en la comprensión de mecanismos moleculares que, según algunos, parecen estar a la base de la herencia epigenética transgeneracional. Ahora bien, como explican Choi y Mango (2014), para poder afirmar que un individuo les transmitió un fenotipo adquirido a generaciones siguientes, es necesario que se confirmen tres fenómenos: (1) la codificación de los cambios en el individuo de la generación P0 (parental); (2) la herencia de la información epigenética a la generación F1 (primera generación filial); (3) la reemergencia o recuperación (retrieval en inglés) del fenotipo en las futuras generaciones. Es en la primera de esas tres fases que el ambiente puede entrar en juego como detonante del cambio, siendo ejemplos de factores inductores de la herencia epigenética transgeneracional: la alimentación, las toxinas, los olores y las fuentes de estrés. Asimismo, ciertas modificaciones a nivel de las histonas (por ejemplo su metilación) pueden estar implicadas en una o más de esas fases. De hecho, tal como señalan Heard y Martienssen (2014), la metilación del ADN es el mecanismo de herencia epigenética transgeneracional más estudiado; y varios tipos de $\mathrm{ARN}$ son otros ejemplos de moléculas implicadas en la herencia epigenética transgeneracional, por ejemplo moléculas de ARN no codificantes.

De más está señalar que Lamarck no habría podido hablar de cromatina, metilación ni ARN. De hecho, al pensar en la teoría lamarckiana de la evolución y en la epigenética, viene a la mente el concepto kuhniano (i.e. de Thomas Kuhn) de inconmensurabilidad; por supuesto, en el caso de Lamarck y la epigenética no se trata del paso de un viejo paradigma coronado de éxito a otro, pero sí se tiene la impresión de una intraducibilidad entre los conceptos del mundo de Lamarck y los del actual. Hasta aquí sigue siendo entonces válida la interrogante: ¡cómo explicar mejor la frecuente asociación entre el nombre de Lamarck y el de la epigenética?

\section{Lamarck y la epigenética: una asociación basada en errores}

Antes que nada, la fuerte asociación entre Lamarck y la herencia de caracteres adquiridos se debe a la difundida creencia de que dicho francés fue el padre de esta idea. Por ejemplo Bucher (2013), en su reseña del libro Epigenetics in Health and Disease, asegura que la historia de la epigenética comienza con teorías "primero propuestas por Jean-Baptiste Lamarck" (p.1). En cuanto a Choi y Mango (2014), le asignan a la idea de la herencia de caracteres adquiridos una antigüedad de dos siglos. Por su parte, Heard y Martienssen (2014) sostienen que la herencia de caracteres adquiridos fue "primero" propuesta por botánicos: Lamarck y Lysenko.

En realidad, la idea es muchísimo más vieja, dado que se puede rastrear hasta la Antigüedad, por ejemplo en más de algún seguidor de Hipócrates (Landman, 1993). En la época de Lamarck se consideraba un hecho ampliamente aceptado (Burkhardt, 2013; Choi \& Mango, 2014; Landman, 1993), como ya se había señalado. De hecho, entre los predecesores de Lamarck que defendieron la misma idea, pero en el siglo XVIII, puede mencionarse a LeRoy y al marqués de Condorcet (Burkhardt, 2013). 
Para Burkhardt (2013), la originalidad de Lamarck respecto a esta noción antigua era en realidad la postura de que la herencia de caracteres adquiridos era "un agente de cambio ilimitado". Esta postura se oponía al fijismo que solía atribuírsele a la creación divina (la idea de un mundo creado por Dios, mundo que se concebía como acabado y fijo, al menos en lo que concierne a las criaturas vivientes) y hay quien considera que la de Lamarck fue "la primera teoría estructurada que proponía la transformación progresiva de las especies" (David, Cohen, \& Dessaint, 2009, p. 2).

Por supuesto, es al entrar en estos terrenos cuando viene a la mente el nombre de Darwin, cuya teoría de la evolución establece un supuesto contraste respecto a Lamarck y su herencia de caracteres adquiridos. Dado que la síntesis moderna o síntesis neodarwiniana combinó el mecanismo darwiniano de la selección natural con una genética que incluía aportes mendelianos y aportes deterministas de Weismann, gran opositor de la idea de la herencia de caracteres adquiridos (Burkhardt, 2013; Landman, 1993), al parecer se formó una nebulosa de ideas en que se asocia fuertemente el nombre de Darwin con el determinismo genético (y a veces hasta con lo mendeliano); y a esa nebulosa hay que agregar, como añadido más reciente, a las mutaciones de las secuencias del ADN como fuente de variación.

El conjunto resultante se suele oponer a otra nebulosa, en la que el nombre de Lamarck se asocia fuertemente con la herencia de caracteres adquiridos por la influencia del ambiente (de hecho, otra creencia errónea es que para Lamarck, el ambiente tenía un efecto directo de modificación en los individuos). Por ejemplo, Smythies, Edelstein y Ramachandran (2014) mencionan que la teoría de Darwin contribuyó al eclipse de la teoría lamarckiana, según la cual los cambios ambientales provocaban cambios corporales (como si en Lamarck ese efecto fuera directo), pero que en la actualidad, al reconocerse el papel de factores ambientales en la modificación de la relación genotipo-fenotipo, las ideas de Lamarck, en una versión modificada, empiezan a gozar de cierta aceptación. Como se verá un poco más adelante, aquí lo cuestionable es oponer radicalmente la idea de la herencia de caracteres adquiridos a la teoría de Darwin, y asociar dicha idea solamente con Lamarck.

La confusión generada por los dos grandes grupos de ideas mencionados es aún más evidente al leer a Balter (2000), quien llega a afirmar que Darwin, a diferencia de Lamarck, había postulado que la adaptación era impulsada por la selección natural de altera- ciones genéticas. Jablonka y Lamb (2005, citadas por West-Eberhard, 2007, p. 447) también se refieren a "la versión común de la teoría de la evolución, de Darwin" la cual consistiría en que "la adaptación ocurre a través de la selección natural de variaciones genéticas azarosas". En este caso, lo discutible sería la propiedad del adjetivo "genético", actualmente cargado de significados posteriores a la teoría de Darwin.

Por otro lado, en ocasiones la transmisión transgeneracional de fenotipos que no se explica por un cambio de la secuencia de los nucleótidos (de los genes normalmente considerados responsables de esos fenotipos) es automáticamente asociada con la herencia de caracteres adquiridos, y a veces hasta calificada de no genética. Es, por ejemplo, lo que da a entender el siguiente pasaje: "Recently, the two-centuries old idea of the inheritance of acquired traits has been rekindled. Scientists started to notice the non-genetic inheritance of new phenotypes, which is now called transgenerational epigenetic inheritance" (Choi \& Mango, 2014, p. 1440). Por ello, cuando la epigenética es definida como campo de estudio de "la emergencia y herencia de nuevos fenotipos en ausencia de cambios en la secuencia del ADN en el genoma" (Choi \& Mango, 2014, p. 1440), al desafiar la manera clásica de pensar el determinismo genético, parece sacar automáticamente de su sepultura a la vieja idea de la herencia de caracteres adquiridos y, por lo tanto, a Lamarck.

De hecho, un planteamiento muy común es aquel según el cual Lamarck creía en la herencia de caracteres adquiridos, mientras que Darwin creía en la selección natural (sin duda somos muchos los que hemos tenido en nuestras manos más de algún libro de texto que establecía esa oposición). Francès (2012), por ejemplo, enuncia:

Mientras Darwin afirmaba que aquellos que eran más aptos sobrevivían y transmitían sus características a la descendencia, originando así el cambio progresivo de las características de las diferentes especies, Lamarck afirmaba que las características que los individuos adquirían a lo largo de su vida se podían transmitir a la descendencia. (p. 5).

Sin embargo, ¡oh, sorpresa!, Darwin también creía en la herencia de caracteres adquiridos (Cubas, Vincent, \& Coen, 1999, citados por Balter, 2000; Landman, 1993), así como en la influencia del uso y de la falta de uso de las partes corporales en dichos caracteres 
heredados (Burkhardt, 2013; Choi \& Mango, 2014; Ho, 1996). Es más, en el capítulo V de El Origen de las Especies, en la sección "Efectos del uso y de la falta de uso", Darwin emplea una retórica que se parece muchísimo a la de Lamarck en el siguiente pasaje (Locker, s.f.), aunque no haya citado explícitamente al francés (Ho, 1996): "puede haber poca duda de que el uso, en nuestros animales domésticos, fortalece y aumenta algunas partes, y la falta de uso las reduce; y que esas modificaciones son heredadas" (Darwin, 1859). Compárese con las dos leyes que había enunciado Lamarck en 1809 (recordando que, en su contexto académico, el término generación se refería más o menos a lo que hoy llamamos reproducción):

\section{Primera Ley.}

En todo animal que no ha sobrepasado el término de sus desarrollos, el empleo más frecuente y sostenido de un órgano cualquiera, fortalece poco a poco ese órgano, lo desarrolla, lo aumenta, y le da una potencia proporcional a la duración de ese empleo; mientras que la falta constante de uso de tal órgano, lo debilita insensiblemente, lo deteriora, disminuye progresivamente sus facultades, $\mathrm{y}$ termina por hacerlo desaparecer.

Segunda Ley.

Todo lo que la naturaleza ha hecho adquirir o perder a los individuos por influencia de las circunstancias a las que su raza se encuentra desde hace tiempo expuesta, y, en consecuencia, por influencia del empleo predominante de tal órgano, o por la [influencia] de una falta constante de uso de tal parte; ésta lo conserva mediante la generación a los nuevos individuos que provienen de aquellos [...]. (Lamarck, 1809)

No obstante, más tarde el término neodarwinismo fue aplicado a Weismann y sus seguidores, todos los cuales se oponían a la herencia de caracteres adquiridos (Haig, 2007); esto ciertamente contribuyó a la confusión posterior, que se ha traducido en vincular directamente a Darwin con tales añadidos ulteriores.

En realidad, puede apreciarse que no es la presencia/ausencia de la idea de la herencia de caracteres adquiridos lo que hace la diferencia entre Lamarck y Darwin, sino la ausencia/presencia de la idea de selección natural. No es con Darwin, sino con la convicción de Weismann de que los cambios ocurridos a nivel somático no podían alcanzar las células germinales (Heard \& Martienssen, 2014; Ho, 1996), que el azar entró en escena, expulsando a la posibilidad de influencia directa del ambiente sobre los caracteres heredados. Es por ello que los cambios epigenéticos, aun cuando son detonados por el ambiente y heredables a través de varias generaciones, no justifican el tipo de desenterramiento de que Lamarck está siendo objeto, puesto que se estima que están sometidos a la selección natural, y la combinación "cambios detonados por el ambiente heredables" + "selección natural" está en todo caso más cerca de la teoría de Darwin que de la lamarckiana. De hecho, en El Origen de las Especies, Darwin (1859) identificó "la herencia de caracteres adquiridos como una de las fuentes de variación sobre las cuales la selección natural actúa" (en palabras de Burkhardt, 2013, p. 802). En este sentido, aun Jablonka y Lamb, quienes se autocalifican como lamarckianas, reconocen que la herencia lamarckiana de caracteres puede explicar la adaptación, pero no la adaptabilidad, y que esta última solamente es explicable con la ayuda de la selección natural darwiniana (citado por Ho, 1996). En todo caso, como indican Heard \& Martienssen (2014, p. 104), "a pesar de que la variación epigenética heredable claramente existe en la naturaleza, es muy importante distinguir entre la epivariación azarosa sobre la que actúa la selección y la variación epigenética inducida por el ambiente" (evidentemente, es esta segunda la que se aproximaría más a lo genuinamente lamarckiano).

Esta última cita ejemplifica las precauciones que es necesario tomar antes de hablar a la ligera sobre un regreso de Lamarck. Asimismo, según indica Szyf (2014), si bien es cierto que varios estudios epidemiológicos en humanos e investigaciones realizadas con modelos animales sugieren una transmisión no genética de la experiencia, y de caracteres adquiridos en respuesta a la exposición a pesticidas, y si bien algunos de esos estudios han demostrado que los rasgos adquiridos se transmitieron por la vía de la línea germinal más allá de la última generación cuya línea germinal fue directamente expuesta al factor de interés, falta determinar si se trata de un fenómeno organizado, dirigido, o si los factores a los cuales los padres fueron expuestos simplemente aumentaron el ruido estocástico en el epigenoma, resultando en una distribución modificada de fenotipos en las generaciones siguientes (lastimosamente, Szyf no especifica de qué estudios se trata exactamente).

Por otra parte, incluso Jablonka y Lamb (1995, citadas por Ho, 1996), quienes habrían presentado ejemplos de evidencias a favor de la existencia de variaciones epigenéticas dirigidas (no azarosas), habrían 
reconocido que no todas son adaptativas, puesto que algunas son perjudiciales para el organismo correspondiente (Ho, 1996). De hecho, de acuerdo con Heard y Martienssen (2014), al igual que las mutaciones convencionales (genéticas), la mayor parte de variaciones epigenéticas son neutras o bien nocivas.

En ese sentido, tras leer por ejemplo al convincente Haig (2007), desenterrar a Lamarck resulta francamente ocioso, dado que no solo lo esencial de Darwin, sino incluso lo esencial del neodarwinismo parece salir invicto tras los descubrimientos epigenéticos. Las mutaciones epigenéticas no serían más que una fuente de variación adicional a la que proveen las mutaciones clásicas (Ho, 1996) y constituirían una propiedad del genoma mismo, que habría evolucionado gracias a la selección natural (Haig, 2007).

Haig (2007) añade que, por otra parte, las mutaciones convencionales también pueden deberse a la acción directa del ambiente (radiaciones, etc.), lo que contradice la naturaleza revolucionaria de los descubrimientos sobre la herencia de caracteres adquiridos en el caso de la epigenética - un malentendido que Haig atribuye al hecho de que este último término no tiene un significado único.

A propósito de polisemia, otra fuente de equivocación respecto a Lamarck es la diversidad de significados que adoptaron términos derivados de su nombre, como lamarckismo o lamarckiano (de la misma manera en que el término darwinismo no siempre corresponde a todo lo que Darwin sostuvo). Aquí la intención no es ahondar exhaustivamente en esa gama de matices, sino solamente referirnos a un caso, el del adjetivo neolamarckiano. De hecho, si los recientes descubrimientos de la epigenética han desenterrado a alguien, no parece tratarse de Lamarck, sino más bien de los neolamarckianos franceses de los siglos XIX-XX, ya que para ellos "la adaptación era el resultado de una acción físicoquímica directa del ambiente en los organismos y su protoplasma, y la transmisión de esas modificaciones a la descendencia" (Morange, 2010, p. 515). Además, a diferencia de Lamarck -por obvias razones-, consideraban esa transmisión como un complemento de la selección natural darwiniana. A ello puede añadirse que, desde su enfoque materialista, querían descubrir los mecanismos subyacentes gracias a experimentos de laboratorio (Morange, 2010). Caullery, por ejemplo, le habría acordado gran importancia tanto al ambiente (como motor de la evolución) como a la genética (Morange, 2010), una mezcla más cercana al discurso epigenético actual. De hecho, Morange propone otro punto en común entre tales neolamarckianos y los epigenetistas: las dificultades para conciliar "la existencia de la plasticidad y la transmisión hereditaria estable de las modificaciones adquiridas a través de esta plasticidad" (p. 517). En otras palabras, asociar la epigenética con lo lamarckiano tendría más cabida si se le antepone a este adjetivo el prefijo neo.

Ahora bien, existen indicios de que las mutaciones epigenéticas sí podrían tener el potencial de ser adaptativas y aun de "responder a desafíos ambientales" (Heard \& Martienssen, 2014). Por otra parte, la importancia de tomar distancia respecto al neodarwinismo clásico reside en que las variaciones epigenéticas podrían permitir una adaptación al ambiente más rápida que la explicada por mutaciones clásicas (Richards, 2006, citado por Heard \& Martienssen, 2014). ¿Sí está ocurriendo entonces una pequeña revolución, después de todo? De ser así, ¿habrá en ella cierto espacio para la contribución de Lamarck respecto de una evolución no sujeta a la selección natural -sino dirigida- y de la herencia de nuevos hábitos adquiridos en respuesta a cambios ambientales?

\section{¿Está de vuelta una parte de Lamarck después de todo?}

Hay que reconocer que en este siglo, ciertas investigaciones han revelado hechos sorprendentes que inspiran la evocación de Lamarck. Es el caso del estudio de Kaati, Bygren y Edvinsson (2002) sobre algunos efectos de la nutrición de niños (en un período específico de su crecimiento, previo a la pubertad) sobre la salud de sus futuros nietos. Si aquellos niños fueron sobrealimentados, los nietos correrían un mayor riesgo de morir por diabetes (cuatro veces más), y los investigadores sostenían que "un sesgo de selección parecía improbable" en su estudio.

Un segundo ejemplo sorprendente, aunque concerniente apenas a las generaciones $\mathrm{P} 0, \mathrm{~F} 1$ y F2, es el de la herencia de un comportamiento adquirido por parte del ratón, aunque cabe aclarar que, tal como Heard y Martienssen (2014) lo exponen, cuando las transmisiones de caracteres adquiridos no alcanzan más que esas generaciones, pueden explicarse sin recurrir al concepto de transmisión transgeneracional, dado que el factor ambiental detonante del cambio podría afectar directamente a los gametos en las gónadas de la generación $\mathrm{P} 0$, alcanzando automáticamente a la generación F1 y, si el animal afectado es una hembra y está embarazada 
al momento de ser expuesta al factor ambiental, tanto los fetos en su interior como los gametos de estos últimos pueden ser directamente afectados, alcanzándose automáticamente a la generación F2. Ahora bien, volviendo al caso sorprendente, se condicionó a ratones al asociar un olor específico (de acetofenona) a un choque eléctrico ligero que suscitaba una reacción de sobresalto, y resultó que esta reacción fue transmitida a los descendientes (F1 y F2) que no fueron sometidos al condicionamiento traumático; es más, ese comportamiento adaptativo no fue la única modificación que apareció en los descendientes, sino también diferencias identificables en los niveles neuroanatómico y epigenético (Dias \& Ressler, 2014). Algunos descendientes nacieron incluso con un bulbo olfativo modificado, en el cual algunos glomérulos, que correspondían al olor específico, eran más grandes. Los investigadores se aseguraron de que la transmisión hubiera tenido lugar por la vía de la línea germinal y no a través de un aprendizaje cultural, pues se valieron de la fertilización in vitro (Szyf, 2014). Ahora bien, quedan en el aire dos interrogantes: si la trasmisión se habría dado más allá de la generación F2, y qué tan común o extraordinario es ese tipo de transmisión de un comportamiento.

En todo caso, en los mamíferos (a diferencia de lo que sucede con las plantas), las marcas epigenéticas que podrían ser transmitidas de una generación a otra (metilación del ADN, por ejemplo) son normalmente borradas en la línea germinal (Heard \& Martienssen, 2014) y, al menos hasta hace recientemente, no se había documentado la transmisión de caracteres adquiridos por más de tres generaciones. El famoso ejemplo del cuello de la jirafa alargándose durante varias generaciones de una manera lamarckiana sigue constituyendo entonces un escenario difícil de concebir.

De hecho, parece que generalmente la transmisión epigenética transgeneracional de caracteres tiende a disminuir a lo largo de las generaciones hasta desvanecerse, una vez que el factor ambiental detonante del cambio ha desaparecido (Burggren, 2014). En este punto, podría injustamente pensarse que la transmisión de caracteres a lo largo de pocas generaciones sería incompatible con las ideas de Lamarck. Sin embargo, en su curso de 1802, explicó que una modificación adquirida por un órgano, por efecto de un hábito de uso suficiente, se transmitía (siempre y cuando fuera común a los progenitores) a los descendientes "sometidos a las mismas circunstancias" (Lamarck, 1802, p. 61). Así, en este caso sí que se le podría dar algo de razón a la luz de la epigenética.
En ese sentido, otro caso interesante que podría ser tildado de lamarckiano, pero que no corresponde con la observación anterior $-\mathrm{y}$ que por lo tanto, a pesar de las apariencias, se constituye en un punto en contra de la teoría de Lamarck- es el de la herencia de un comportamiento adquirido en el gusano Caenorhabditis elegans. Al parecer, si se exponen cuatro generaciones sucesivas a ciertas sustancias olorosas atrayentes, la mejora del comportamiento de quimiotactismo positivo se mantiene durante más de 40 generaciones (Remy, 2010).

Queda entonces claro que, con o sin Lamarck, vale la pena abrirle un espacio a la posibilidad de que comportamientos modificados a consecuencia de cambios ambientales jueguen un papel en la microevolución.

\section{Conclusión}

Hemos visto que la nueva popularidad de Lamarck relacionada con el desarrollo de la epigenética se basa en varias creencias erróneas, en parte debidas al desconocimiento de su obra y de la de Darwin, así como de la historia de las ciencias de la vida en general. Según esas creencias equivocadas, la herencia de caracteres adquiridos sería una creación original de Lamarck, así como la idea central de su teoría de la evolución, y habría estado ausente en el pensamiento de Darwin. En realidad, Darwin también estaba convencido de la herencia de caracteres adquiridos, por lo que, respecto a los hallazgos de la epigenética, dentro de la cual se le guarda un debido espacio al concepto de selección natural, probablemente sería más certero hablar del regreso de Darwin que del de Lamarck.

Como también se vio, si se trata de asociar este último nombre a la epigenética, en todo caso habría que tomar el adjetivo correspondiente (lamarckiano) y agregarle el prefjio neo para aludir a un cierto retorno de los neolamarckianos franceses, puesto que en ellos podían encontrarse elementos que se acercan a ciertas ideas epigenéticas recientes: una influencia directa del ambiente; el hecho de que esta influencia se produzca a nivel físicoquímico; la posibilidad de transmisión de los cambios resultantes a la progenie; y todo ello, sin excluir el mecanismo de selección natural darwiniano.

En cualquier caso, tomando en cuenta el componente innovador de la teorización de Lamarck, y dado que incluso en algunas palabras de Darwin pareciera haber ecos de sus conceptos, habría que reconocer, como habría dicho el genetista Coen según varias fuentes, que "Lamarck fue un verdadero pionero de la teoría evolutiva". 


\section{Referencias}

Balter, M. (2000). Was Lamarck just a little bit right? Science, 288(5463), 38. doi: 10.1126/science. 288.5463 .38

Bucher, É. (2013). The return of Lamarck? Frontiers in Genetics, 4(10), 1-2. doi: 10.3389/fgene.2013.00010

Burggren, W. W. (2014). Epigenetics as a source of variation in comparative animal physiology - or - Lamarck is lookin' pretty good these days. Journal of Experimental Biology 217 (5), 682-689. doi: 10.1242/jeb.086132

Burkhardt, R. W. (2013). Lamarck, evolution, and the inheritance of acquired characters. Genetics, 194(4), 793-805. doi: 10.1534/genetics. 113.151852

Choi, Y., \& Mango, S. E. (2014). Hunting for Darwin's gemmules and Lamarck's fluid: Transgenerational signaling and histone methylation. Biochimica et Biophysica Acta, 1839(12), 1440-1453. doi: 10.1016/j.bbagrm.2014.05.011

Cubas, P., Vincent, C., \& Coen, E. (1999). An epigenetic mutation responsible for natural variation in floral symmetry. Nature, 401(6749), 157-161. doi: $10.1038 / 43657$

Darwin, C. (1859). The Origin of Species, Chapter 5: Laws of Variation. Recuperado el 11 de Abril de 2017, de The TalkOrigins Archive: http://www. talkorigins.org/faqs/origin/chapter5.html

David, B., Cohen, G., \& Dessaint, J.-P. (2009). Génétique environnementale et épigénétique ou la réhabilitation de J. B. Lamarck. Recuperado el 19 de Diciembre de 2014, de archives-ouvertes.fr: https://halshs.archives-ouvertes.fr/pasteur-00434412/document

Dias, B. G., \& Ressler, K. J. (2014). Parental olfactory experience influences behavior and neural structure in subsequent generations. Nature Neuroscience, 17(1), 89-96. doi: 10.1038/nn.3594

Francès, F. (2012). ¿Vuelve Lamarck? Gaceta Internacional de Ciencias Forenses, (4), 5-6.

Haig, D. (2004). The (dual) origin of epigenetics. Cold Spring Harbor Symposia on Quantitative Biology. LXIX, págs. 67-70. New York: Cold Spring Harbor Laboratory Press.
Haig, D. (2007). Weismann rules! OK? Epigenetics and the Lamarckian temptation. Biology and Philosophy, 22(3), 415-428. doi: 10.1007/s10539-0069033-y

Haig, D. (2012). Commentary: The epidemiology of epigenetics. International Journal of Epidemiology, 41(1), 13-16. doi: 10.1093/ije/dyr183

Heard, E., \& Martienssen, R. A. (2014). Transgenerational epigenetic inheritance: Myths and mechanisms. Cell, 157(1), 95-109. doi: 10.1016/j. cell.2014.02.045

Ho, M. W. (1996). Why Lamarck won't go away. Annals of Human Genetics, 60(1), 81-84. doi: 10.1111/j.1469-1809.1996.tb01176.x

Jablonka, E., \& Lamb, M. J. (1995). Epigenetic Inheritance and Evolution: The Lamarckian Dimension. Oxford: Oxford University Press.

Jablonka, E., \& Lamb, M. J. (2005). Evolution in Four Dimensions. Genetic, Epigenetic, Behavioral, and Symbolic Variation in the History of Life. Cambridge, Massachusetts: The MIT Press.

Kaati, G., Bygren, L., \& Edvinsson, S. (2002). Cardiovascular and diabetes mortality determined by nutrition during parents' and grandparents " slow growth period. European Journal of Human Genetics, 10(11), 682-688. doi: 10.1038/ sj.ejhg.5200859

Lamarck, J.-B. (1801). Système des animaux sans vertèbres. Recuperado el 3 de Diciembre de 2017, de Euvres et rayonnement de Jean-Baptiste Lamarck: http://www.lamarck.cnrs.fr/ice/ ice_book_detail.php?lang=fr\&type $=$ text\&bd$\mathrm{d}=$ koyre_lamarck\&table=ouvrages_lamarck\&bookId $=\overline{7} \&$ typeofbookId $=1 \&$ num $=0$

Lamarck, J.-B. (1802). Recherches sur l'organisation des corps vivans. Recuperado el 4 de Diciembre de 2017, de Euvres et rayonnement de Jean-Baptiste Lamarck: http://www.lamarck.cnrs.fr/ice/ ice_book_detail.php?lang=fr\&type $=$ text\&bd$\mathrm{d}=$ lamarck\&table $=$ ouvrages_lamarck\&book$\mathrm{Id}=9$ \&typeofbookId=1\&num=0

Lamarck, J.-B. (1809). Philosophie zoologique. Recuperado el 4 de Diciembre de 2017, de Euvres et rayonnement de Jean-Baptiste Lamarck: http:// www.lamarck.cnrs.fr/ice/ice_book_detail.php?lan $\mathrm{g}=$ fr\&type $=$ text\&bdd $=$ lamarck\&table $=$ ouvrages lamarck\&bookId=29\&typeofbookId=1\&num $=0$ 
Lamarck, J.-B. (1815-1822). Histoire naturelle des animaux sans vertèbres. Recuperado el 4 de Diciembre de 2017, de Euvres et rayonnement de Jean-Baptiste Lamarck: http://www.lamarck.cnrs. $\mathrm{fr} /$ ice/ice_book_detail.php?lang $=$ fr\&type $=$ text\&b $\mathrm{dd}=$ lamarck\&table $=$ ouvrages_lamarck\&bookId= 38\&typeofbookId $=1 \&$ num $=0$

Landman, O. (1993). Inheritance of acquired characteristics revisited. BioScience, 43(10), 696-705. doi: $10.2307 / 1312341$

Locker, D. (s.f.). L'épigénétique ou Lamarck pourrait-il avoir raison? Recuperado el 17 de Diciembre de 2014, de http://daniel.locker.perso.sfr. fr/article\%20vulgarisation/resume\%20Darwincor2612010.pdf

Morange, M. (2010). What history tells us: XXII. The French neo-Lamarckians. Journal of Biosciences, 35(4), 515-517. doi: 10.1007/s12038-010-0058-7

Morange, M. (2013). What history tells us: XXXII. The long and tortuous history of epigenetic marks. Journal of Biosciences, 38(3), 451-454. doi: 10.1007/s12038-013-9354-3

Nanney, D. L. (1958). Epigenetic control systems. Proceedings of the National Academy of Sciences of the United States of America, 44(7), 712-717. doi: 10.1073/pnas.44.7.712

Nicolosi, G., \& Ruivenkamp, G. (2012). The epigenetic turn: Some notes about the epistemological change of perspective in biosciences. Medicine Health Care and Philosophy, 15(3), 309-319. doi: 10.1007/s11019-011-9342-z

Remy, J.-J. (2010). Stable inheritance of an acquired behavior in Caenorhabditis elegans. Current Biology, 20(20), R877-R878, doi: 10.1016/j. cub.2010.08.013
Richards, E. (2006). Inherited epigenetic variation-revisiting soft inheritance. Nature Reviews Genetics, 7(5), 395-401. doi: 10.1038/nrg1834

Ruiz Rejón, M. (2015). Epigenética: ¿vuelve el Lamarckismo? Recuperado el 13 de Abril de 2017, de OpenMind: https://www.bbvaopenmind.com/ epigenetica-vuelve-el-lamarckismo/

Sano, H. (2010). Inheritance of acquired traits in plants, reinstatement of Lamarck. Plant Signaling \& Behavior, 5(4), 346-348. doi: 10.4161/psb.5.4.10803

Sawan, H., \& Parvizi, J. (2013). Science of epigenetics: Lamarck was right after all. Recuperado el 26 de Diciembre de 2014, de Orthopedics Today: http://www.healio.com/orthopedics/ biologics/news/print/orthopedics-today/\%7Bce137c67-1e1d-41a9-9892-2734f1b9b4c7\%7D/ science-of-epigenetics-lamarck-was-right-after-all Smythies, J., Edelstein, L., \& Ramachandran, V. (2014). Molecular mechanisms for the inheritance of acquired characteristics - exosomes, microRNAs huttling, fear and stress: Lamarck resurrected? Frontiers in Genetics, 133(5). doi: 10.3389/ fgene.2014.00133

Szyf, M. (2014). Lamarck revisited: epigenetic inheritance of ancestral odor fear conditioning. Nature Neuroscience, 17(1), 2-4. doi: 10.1038/nn.3603

West-Eberhard, M. J. (2007). Dancing with DNA and flirting with the ghost of Lamarck. Biology and Philosophy, 22(3), 439-451. doi: 10.1007/s10539006-9034-x 